11 | 2007

Varia

Présentation et mise en valeur des sites archéologiques religieux en milieu urbain

Luxeuil, projet de table ronde, 25-26 avril 2008

Sébastien Bully et Christian Sapin

(2) OpenEdition

Journals

Édition électronique

URL : https://journals.openedition.org/cem/1521

DOI : 10.4000/cem.1521

ISSN : 1954-3093

Éditeur

Centre d'études médiévales Saint-Germain d'Auxerre

Édition imprimée

Date de publication : 15 août 2007

ISSN : 1623-5770

Référence électronique

Sébastien Bully et Christian Sapin, « Présentation et mise en valeur des sites archéologiques religieux en milieu urbain », Bulletin du centre d'études médiévales d'Auxerre | BUCEMA [En ligne], 11 | 2007, mis en ligne le 30 août 2007, consulté le 22 septembre 2022. URL : http://journals.openedition.org/cem/1521 ; DOI : https://doi.org/10.4000/cem.1521

Ce document a été généré automatiquement le 22 septembre 2022.

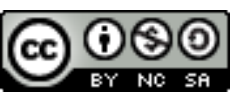

Creative Commons - Attribution - Pas d'Utilisation Commerciale - Partage dans les Mêmes Conditions 4.0 International - CC BY-NC-SA 4.0

https://creativecommons.org/licenses/by-nc-sa/4.0/ 


\title{
Présentation et mise en valeur des sites archéologiques religieux en milieu urbain
}

\author{
Luxeuil, projet de table ronde, 25-26 avril 2008
}

Sébastien Bully et Christian Sapin

1 Ces dernières décennies, l'archéologie en milieu urbain est principalement devenue synonyme d'archéologie de sauvetage puis d'archéologie préventive. Les recherches ont révélé des ensembles religieux de l'Antiquité tardive et du Moyen Âge souvent méconnus jusqu'alors et qui ont largement fait progresser notre connaissance des premiers groupes épiscopaux, des monastères urbains ou péri-urbains, des basiliques funéraires ou bien encore des églises paroissiales. La qualité des vestiges et l'intérêt suscité par ces découvertes ont parfois conduit les collectivités - souvent les municipalités - à engager des travaux visant à leur valorisation. Dès lors, et au-delà des retombées scientifiques et de leur intérêt à court terme pour le grand public, la question s'est souvent posée de la conservation de vestiges souvent fragiles (tombes, enduits peints, sols...) et de leur gestion à plus long terme dans des espaces souvent découverts et au cœur des différentes contraintes de la ville (circulation, stationnement, commerces, etc.). C'est à partir de ces constats et en préalable à un projet de fouille programmée portant sur l'église funéraire Saint-Martin de Luxeuil, que nous projetons d'organiser une rencontre afin de traiter de ces questions.

2 À la lumière des expériences acquises ces trente dernières années dans ce domaine, la table ronde se propose de réunir différents intervenants (archéologues, architectes, muséographes, représentants de la maitrise d'ouvrage) pour présenter des exemples de recherches et de mise en valeur, tant en France qu'à l'étranger (les exemples pressentis sont ceux de Limoges, la Charité-sur-Loire, Saint-Denis, Brioude, Arles, Auxerre, Grenoble, Besançon, Aoste, Genève, Tournai). Après l'exposé des résultats scientifiques, les intervenants (archéologues, architectes, élus ou représentants de villes) présenteront les choix de conservation et les différentes stratégies de valorisation mises en œuvre. Cette rencontre et les discussions qui en découleront devraient 
permettre de réfléchir à la pertinence et à l'ampleur d'une valorisation des vestiges de Luxeuil, tel que le souhaiterait la municipalité.

3 La table ronde se tiendra à Luxeuil-les-Bains et réunirait une cinquantaine de personnes. 